\title{
Awareness and Attitude regarding Cardiovascular Diseases among the Adolescents Studying in Grade 12 in Makawanpur Multiple Campus in Nepal
}

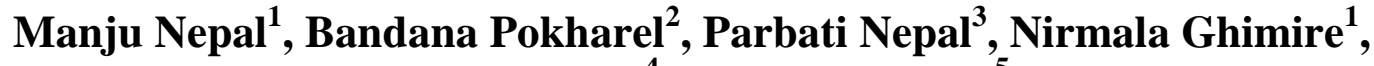 \\ Nira Neupane ${ }^{4}$, Deepika Khadgi ${ }^{5}$ \\ ${ }^{1}$ Assistant Professor, Patan Academy of Health Sciences, School of Nursing and Midwifery, Lalitpur Nursing \\ Campus Sanepa, Nepal \\ ${ }^{2}$ Associate Professor, Lumbini Medical College and Teaching Hospital, Tansen, Pravas \\ ${ }^{3}$ Assistant Professor, Lumbini Medical College and Teaching Hospital, Tansen, Pravas \\ ${ }^{4}$ Associate Professor, Sanjeevani College of Medical Sciences, Butwal \\ ${ }^{5}$ Lecturer, TUIOM, Biratnagar Nursing Campus \\ Corresponding Author: Manju Nepal
}

\begin{abstract}
Objective: Cardiovascular diseases (CVD) are the leading cause of death worldwide. It is crucial to detect risk factors and behaviors throughout childhood and adolescence to advocate as a strategy to reduce risk of CVD in adulthood. The objective of this study was to assess the awareness and attitude regarding Cardiovascular Diseases among the Adolescents Studying in Grade 12 in Makawanpur Multiple Campus in Nepal.

Materials and Methods: This descriptive cross sectional analytical study was conducted among 135 adolescents studying in grade 12 in Makwanpur Multiple Campus, Hetauda, Nepal. The selection of study site was done purposively. A structured self-developed questionnaire was used to assess the awareness on cardiovascular disease and five-point Likert scale to assess attitude regarding cardiovascular diseases were used. Statistical package for social sciences (SPSS) version 20 was used for data analysis. Both descriptive (frequency, percentage, and mean) and inferential statistics (chisquare) were used to analyze the data.

Results: Among 135 respondents, 17(12.6\%) respondents had inadequate awareness, 52(38.5\%) had moderate awareness and 66(48.9\%) had adequate awareness. The mean awareness on cardiovascular disease was $11.90 \pm 2.83$. Similarly more than half of respondents $69(51.1 \%)$ had favorable attitude toward cardiovascular disease.

A statistically significant association between gender of the respondents and awareness level was found as Chi-square p value less than $0.05(\mathrm{p}=.011)$ at $5 \%$ level of significance. Similarly, statistically significant association between family history of CVD and attitude on cardiovascular disease was found at 5\% level of significance ( $\mathrm{p}$ value $=.027$ ).

Conclusion: Nearly half of respondents had adequate level of awareness regarding cardiovascular diseases whereas more than half of respondents had favorable attitude toward cardiovascular disease.
\end{abstract}

Keywords: Adolescent, Attitude, Awareness, Cardiovascular Diseases

\section{INTRODUCTION}

The global burden of cardiovascular diseases is alarming. Every year, 17.1 million lives are claimed by the global burden of heart disease and stroke, $82 \%$ of cardiovascular diseases are in the developing world. ${ }^{1}$ South Asian children could be at a greater risk of developing cardiovascular risk factors at an earlier stage, thus, timely interventions are imperative $^{2}$. Psychological stress reactivity is associated with atherogenesis in 
youth. Atherosclerotic changes begin in the early ages and progress to great extent during adolescence. ${ }^{2}$ Adolescents are vulnerable to coronary artery diseases due to lifestyle related behavior risk factors such as physical inactivity, unhealthy habits, snacking on energy dense foods, unhealthy competition and increasing level of stress. $^{3,4,5}$

Although cardiovascular disease occurs in the middle age or later, risk factor (smoking, dietary factors are determined to great extent by behaviours learnt in childhood and continued to adulthood. ${ }^{6}$ Cardiovascular diseases can be prevented by educating younger population to promote their healthy lifestyle behavior. ${ }^{7}$

More than one-half of young adults aged 18-24 years have at least one coronary heart disease (CHD) risk factor and nearly one-quarter have advanced atherosclerotic lesions. The extent of atherosclerosis is directly correlated with the number of risk factors. Unhealthy dietary choices made by this age group contribute to weight gain and dyslipidemia. ${ }^{8}$

The findings of a school based cross sectional study done among adolescents in Nepalgunj municipality of Banke district showed $76.9 \%$ of adolescents had least one risk factor of cardiac disease. Un-protective HDL was the commonest metabolic risk factors. ${ }^{9}$ Similarly, only small percentages $(11 \%)$ of the respondents had a good level of knowledge regarding CVD risk factors but approximately a quarter of the respondents $(71.9 \%)$ had a cardiovascular risk seeking attitude was found in a study conducted in Lekhnath Metropolitan city among students. ${ }^{10}$

Atherosclerotic changes begin in the early ages and progress to great extent during adolescence. So the aim of this study was to make aware about the cardiovascular diseases and take preventive measures before developing the disease among the adolescents.

\section{MATERIALS AND METHODS Study design and settings:}

A cross-sectional analytic study design was used to conduct a study on awareness and attitude regarding cardiovascular diseases among adolescents studying in grade 12 . The study was conducted in Malwanpur Multiple Campus, Hetauda after taking ethical approval from the Ethical Review Board of Nepal Health Research Council (Ref. 1456/2020). At first selection of study site was done purposively. There were total three faculties in grade 12 in Makawanpur Multiple Campus (Humanities, Science and Management). Grade 12 Students studying in Humanities were selected by the simple random sampling using lottery method. There were total of 407 students studying in humanities faculty. Among them, 135 students were included in the study using a systematic random sampling. The first subject was selected randomly by lottery method using attendance register, later every sample was selected by using sampling interval of three from the attendance register. Data was collected using self-developed structured questionnaire in Nepali version on $24^{\text {th }}$ February $2021(2077 / 11 / 12)$ at the classroom setting by the researchers.

Before collecting the data minor ascent consent in written form was taken from the each respondent. Respondents were requested to fill up the questionnaire with in the class period. The purpose of the study was explained to respondents. Respondents were informed that their participation is fully voluntary and they have freedom to withdraw from the study at any time without any penalty. Respondents were assured that the confidentiality of the study is maintained all the time during study period by utilizing the data only for research purpose. Anonymity was maintained by using code number instead of using name of the respondents in questionnaire. Data were checked, reviewed and coded and entered in the SPSS version 20 after the completion of data collection. Both 
descriptive (frequency, percentage, and mean) and inferential statistics (chi-square) were used to analyze the data according to nature of variables.

\section{Development of questionnaire and validation}

Questionnaire was developed after extensive review of related literature on the awareness and attitude regarding cardio vascular disease. Questions were thoroughly structured, reviewed and revised and necessary modifications were made so that it could truly assess the basic awareness and attitude regarding cardiovascular diseases among adolescents. For the validation of the questionnaire, a through consultation with subject expert Assistant Professor Vivechana Shakya (PAHS) was done. Then pretesting was conducted among the 13 students studying in management faulty and minor modifications were made in the tool such as rephrasing according to their feedback.

\section{Questionnaire and scoring criteria}

Part one consisted of demographic characteristics of respondents. Part two consisted of 16 questions related to awareness regarding cardiovascular diseases, score one was given for each correct response and zero for incorrect response. The awareness levels were categorized by the following criteria:

- Total score less than $50 \%$ is inadequate awareness

- Total score $50-75 \%$ is moderately adequate awareness

- Total score more than $75 \%$ is adequate awareness

Part three consisted of attitude related questions on cardiovascular diseases in five point Likert scale. Each items was related to cardiovascular diseases and it had 10 statements both positive and negative statements on attitude regarding cardiovascular diseases. Therefore the total score of attitude was 50. Mean was calculated by the total score; mean and above the mean score were classified favorable attitude and below the mean unfavorable attitude on cardiovascular disease.

\section{RESULTS}

Out of 135 respondents, $72(53.3 \%)$ were from 18 years and only $15(11.1 \%)$ respondents from 19 years. The mean age \pm SD of respondent was 17.75 \pm .064 . Regarding the gender, 78(57.8\%) respondents were female. Regarding ethnicity, majority of respondents 47 (34.8\%) were from Bhramin/Chhetri and $120(88.9 \%)$ of respondents were related with Hinduism and 80(59.3\%) of respondents were related with nuclear family (Table 1).

Table 1.Socio-demographic characteristics of respondents', $\mathrm{N}=135$

\begin{tabular}{|l|l|l|}
\hline Characteristics & Frequency & Percentage \\
\hline Age in years & & \\
\hline 17 & 48 & 35.6 \\
\hline 18 & 72 & 53.3 \\
\hline 19 & 15 & 11.1 \\
\hline Mean age \pm SD & $17.75 \pm .064$ & \\
\hline Gender & & \\
\hline Male & 57 & 42.2 \\
\hline Female & 78 & 57.8 \\
\hline Ethnicity & & \\
\hline Bhrahamin/Chhetri & 47 & 34.8 \\
\hline Janajati' & 21 & 15.6 \\
\hline Taraibasi & 37 & 27.4 \\
\hline Dalit & 30 & 22.2 \\
\hline Religion & & \\
\hline Hinduism & 120 & 88.9 \\
\hline Christian & 8 & 5.9 \\
\hline Buddhism & 7 & 5.2 \\
\hline Type of family & & \\
\hline Nuclear & 80 & 59.3 \\
\hline Joint & 55 & 40.7 \\
\hline \multicolumn{2}{|l}{} \\
\hline
\end{tabular}

Table 2 depicts that $97 \%$ of the respondents aware that high blood pressure is a risk factor for CVD, followed by $92.6 \%$ on in sufficient physical activity and $87.4 \%$ on use of tobacco. $65.9 \%$ of the respondents aware that adolescents also have the risk of CVD. Regarding food habit, $85.9 \%$ of the respondents aware that fatty meals increase the cholesterol level in blood followed by $71.1 \%$ on harmful to eat red meat more than three times in a week. Regarding signs of heart disease, $89.6 \%$ of respondents aware that pain in chest is the signs of heart disease followed by $81.5 \%$ on difficulty in breathing. 
Manju Nepal et.al. Awareness and attitude regarding cardiovascular diseases among the adolescents studying in grade 12 in Makawanpur multiple campus in Nepal.

Table 2. Respondents' awareness on cardiovascular diseases, $N=135$

\begin{tabular}{|l|l|l|l|}
\hline Table 2. Respondents' awareness on cardiovascular diseases, N=135 \\
\hline Characteristics & $\begin{array}{l}\text { Yes } \\
\mathbf{N}(\%)\end{array}$ & $\begin{array}{l}\text { No } \\
\text { N }(\%)\end{array}$ & $\begin{array}{l}\text { Don't Know } \\
\mathbf{N}(\%)\end{array}$ \\
\hline Adolescents might be under the risk of cardiovascular diseases & $89(65.9)$ & $17(12.6)$ & $29(21.5)$ \\
\hline It is harmful to eat red meat more than thrice a week & $96(71.1 \%)$ & $10(7.4 \%)$ & $29(21.5 \%)$ \\
\hline Fatty meals increase the cholesterol level in blood & $116(85.9 \%)$ & - & $19(14.1)$ \\
\hline A low carbohydrate and low fat diet is beneficial for heart health & $100(74.1 \%)$ & $8(5.9 \%)$ & $27(20.0 \%)$ \\
\hline Tobacco use is the risk factors for CVD & $118(87.4 \%)$ & - & $17(12.6 \%)$ \\
\hline In sufficient physical activity is the risk factor for CVD & $125(92.6 \%)$ & $6(4.4 \%)$ & $4(3.0 \%)$ \\
\hline Stress, sorrow and burden increases risk of CVD & $120(88.9 \%)$ & - & $15(11.1 \%)$ \\
\hline High blood pressure is a risk factor for CVD & $131(97.0 \%)$ & $2(1.5 \%)$ & $2(1.5 \%)$ \\
\hline Diabetes is a risk factor for CVD & $93(68.9 \%)$ & $2(1.5 \%)$ & $40(29.6 \%)$ \\
\hline Difficulty in breathing is the sign of heart disease & $110(81.5 \%)$ & $12(8.9 \%)$ & $13(9.6 \%)$ \\
\hline Pain in chest is the sign of heart disease & $121(89.6 \%)$ & $6(4.5 \%)$ & $8(5.9 \%)$ \\
\hline Excessive sweating is the sign of heart disease & $46(34.1 \%)$ & $17(12.6 \%)$ & $72(53.3 \%)$ \\
\hline Dizziness is the sign of heart disease & $34(25.2 \%)$ & $21(15.6 \%)$ & $80(59.2 \%)$ \\
\hline Swelling of legs is the sign of heart disease & $38(28.2 \%)$ & $23(17.0 \%)$ & $74(54.8 \%)$ \\
\hline
\end{tabular}

Table 3 depicts that $17(12.6 \%)$ respondents had inadequate awareness, $52(38.5 \%)$ had moderate awareness and $66(48.9 \%)$ had adequate awareness.

Table 3.Respondents' level of awareness on cardiovascular disease, $\mathrm{N}=135$

\begin{tabular}{|l|l|l|}
\hline Level of awareness & Frequency & Percent \\
\hline Inadequate awareness & 17 & 126 \\
\hline Moderate awareness & 52 & 38.5 \\
\hline Adequate & 66 & 48.9 \\
\hline Mean $\pm \mathrm{SD}=11.90 \pm 2.83$ & & \\
\hline
\end{tabular}

Among the total respondents, most of the respondents $(95.6 \%)$ strongly agreed that people with CVD need regular medical checkup followed by $74.1 \%$ of the respondents strongly agreed that daily intake of fruits and vegetables decrease the risk of CVD. The least of the respondents (5.2\%) strongly agreed that high blood pressure is minor problem similarly only $3 \%$ of the respondent strongly agreed that CVD is an old age problem so there is no need to be worried (Table 4.)

Table 4. Distribution of frequency and percentage regarding attitude on cardiovascular disease among adolescent, $\mathrm{N}=135$

\begin{tabular}{|c|c|c|c|c|c|}
\hline \multirow[t]{2}{*}{ Items } & $\begin{array}{l}\text { Strongly } \\
\text { agree }\end{array}$ & Agree & Uncertain & Disagree & $\begin{array}{l}\text { Strongly } \\
\text { Disagree }\end{array}$ \\
\hline & $\mathbf{N}(\%)$ & $\mathbf{N}(\%)$ & $\mathbf{N}(\%)$ & $\mathbf{N}(\%)$ & $\mathbf{N}(\%)$ \\
\hline 1. CVD is hereditary & $54((40 \%)$ & $39(28.9 \%)$ & $18(13.3 \%)$ & $10(7.4 \%)$ & $14(10.4 \%)$ \\
\hline 2. High blood pressure is minor problem ${ }^{\alpha}$ & $7(5.2 \%)$ & $28(20.7 \%)$ & - & $22(16.3 \%)$ & $78(57.8 \%)$ \\
\hline $\begin{array}{l}\text { 3. Daily intake of fruits and vegetable decreases the risk of } \\
\text { heart disease }\end{array}$ & $100(74.1 \%)$ & $14(10.4 \%)$ & $13(9.6 \%)$ & $1(.7 \%)$ & $7(5.2 \%)$ \\
\hline 4. People who are taking fatty/salty diet still healthy ${ }^{\alpha}$ & - & $6(4.4 \%)$ & $26(19.3 \%)$ & $44(32.6 \%)$ & $59(43.7 \%)$ \\
\hline 5. Hypertensive medication should be used for life time & $20(14.8 \%)$ & $35(25.9 \%)$ & $44(32.6 \%)$ & $18(13.3 \%)$ & $18(13.3 \%)$ \\
\hline $\begin{array}{l}\text { 6. People who are physically inactive at day time are more } \\
\text { risk for heart disease }\end{array}$ & $49(36.3 \%)$ & $48(35.6 \%)$ & $23(17.0 \%)$ & - & $15(11.1 \%)$ \\
\hline 7. Being with happy and satisfied prevent heart disease & $72(53.3 \%)$ & $25(18.5 \%)$ & $26(19.6 \%)$ & $8(5.9 \%)$ & $4(3.0 \%)$ \\
\hline 8. People who are taking fast food are still healthy ${ }^{\alpha}$ & - & - & $16(11.8 \%)$ & $22(16.3 \%)$ & $97(71.9 \%)$ \\
\hline 9. CVD is an old age problem, so no need to be worried ${ }^{\alpha}$ & $4(3 \%)$ & $2(1.5 \%)$ & - & $22(16.3 \%)$ & $107(79.3 \%)$ \\
\hline 10. People with CVD need regular medical check up & $129(95.6 \%)$ & - & $5(3.7 \%)$ & $1(.7)$ & - \\
\hline
\end{tabular}

Table 5 shows the respondents' overall attitude regarding cardiovascular disease. More than half of respondents 69(51.1\%) have favorable attitude toward cardiovascular disease.

Table 5. Respondents' level of attitude on cardiovascular disease, $\mathrm{N}=135$

\begin{tabular}{|l|l|l|}
\hline Level of Attitude & Frequency & Percent \\
\hline Unfavorable attitude & 66 & $48.9 \%$ \\
\hline Favorable attitude & 69 & $51.1 \%$ \\
\hline Mean $\pm \mathrm{SD}=41.77 \pm 3.54$ & & \\
\hline
\end{tabular}

Table 6 depicts that there was a significant association between gender of the respondents and awareness level $\left(\chi^{2}=6.415, \quad \mathrm{p}=.011\right) \quad$ similarly mothers' education and family history of CVD also showed the significant association with level of awareness (likelihood ratio $=24.257$, $\mathrm{p}=.000$ ) and (likelihood ratio $=6.508$, $\mathrm{p}=.011$ ) respectively. There was no significant association between type of 
Manju Nepal et.al. Awareness and attitude regarding cardiovascular diseases among the adolescents studying in grade 12 in Makawanpur multiple campus in Nepal.

family and level of awareness $(\mathrm{p}=>.05$ at $95 \%$ confidence interval).

Table 6.Association between Gender, type of family, parental education, family history of CVD with level of awareness on CVD, $\mathbf{N}=\mathbf{1 3 5}$

\begin{tabular}{|c|c|c|c|c|c|}
\hline \multirow[t]{2}{*}{ Variables } & \multirow{2}{*}{$\begin{array}{l}\text { Frequency } \\
(\%)\end{array}$} & \multicolumn{2}{|l|}{ Level of awareness } & \multirow[t]{2}{*}{ Chi-square } & \multirow[t]{2}{*}{ p- value } \\
\hline & & $\begin{array}{l}\text { Inadequate awareness } \\
\mathrm{N}(\%)\end{array}$ & $\begin{array}{l}\text { Moderate to adequate awareness } \\
\mathrm{N}(\%)\end{array}$ & & \\
\hline \multicolumn{6}{|l|}{ Gender } \\
\hline Female & $78(57.8 \%)$ & $5(6.4 \%)$ & $73(93.6 \%)$ & 6.415 & .011 \\
\hline \multicolumn{6}{|l|}{ Type of family } \\
\hline Nuclear & $80(59.3 \%)$ & $7(8.8 \%)$ & $73(91.2 \%)$ & 2.634 & .105 \\
\hline \multicolumn{6}{|l|}{ Fathers' education } \\
\hline Up to primary level & $29(21.5 \%)$ & $5(17.2 \%)$ & $24(82.8 \%)$ & \multirow[t]{2}{*}{.725} & \multirow[t]{2}{*}{.394} \\
\hline Secondary and above & $106(78.5 \%)$ & $12(11.3 \%)$ & $94(88.7 \%)$ & & \\
\hline \multicolumn{6}{|l|}{ Mothers' education } \\
\hline Up to primary level & $47(34.8 \%)$ & $15(31.9 \%)$ & $32(68.1 \%)$ & \multirow[t]{2}{*}{$24.257^{*}$} & \multirow[t]{2}{*}{.000} \\
\hline Secondary and above & $88(65.2 \%)$ & $2(2.3 \%)$ & $86(97.7 \%)$ & & \\
\hline
\end{tabular}

*Likelihood Ratio value

Table 7 showed that there were not statistically significant association between gender, type of family, father's education and mother's education with attitude regarding cardiovascular disease at $95 \%$ confidence interval $\left(\chi^{2}\right.$ p-value $\left.>0.05\right)$.
Significant association between family history of CVD and attitude on cardiovascular disease was found at $95 \%$ confidence interval $\left(\chi^{2}=4.915, \quad p\right.$ value $=.027$ ).

Table 7. Association between Genders, type of family, parental education, family history of CVD with level of attitude on CVD, $\mathbf{N}=\mathbf{1 3 5}$

\begin{tabular}{|c|c|c|c|c|c|}
\hline \multirow[t]{2}{*}{ Variables } & \multirow{2}{*}{$\begin{array}{l}\text { Frequency } \\
(\%)\end{array}$} & \multicolumn{2}{|l|}{ Level of Attitude } & \multirow[t]{2}{*}{ Chi-square } & \multirow[t]{2}{*}{ p-value } \\
\hline & & $\begin{array}{l}\text { Favorable Attitude } \\
\mathrm{N}(\%)\end{array}$ & $\begin{array}{l}\text { Unfavorable Attitude } \\
\mathrm{N}(\%)\end{array}$ & & \\
\hline \multicolumn{6}{|l|}{ Gender } \\
\hline Male & $57(42.2 \%)$ & $27(47.4 \%)$ & $30(52.6 \%)$ & \multirow[t]{2}{*}{0.91} & \multirow[t]{2}{*}{.763} \\
\hline Female & $78(57.8 \%)$ & $39(50.0 \%)$ & $39(50.0 \%)$ & & \\
\hline \multicolumn{6}{|l|}{ Type of family } \\
\hline Nuclear & $80(59.3 \%)$ & $35(43.8 \%)$ & $45(56.2 \%)$ & \multirow[t]{2}{*}{2.075} & \multirow[t]{2}{*}{.150} \\
\hline Joint & $55(40.7 \%)$ & $31(56.4)$ & $24(43.6 \%)$ & & \\
\hline \multicolumn{6}{|l|}{ Fathers' education } \\
\hline Up to primary level & $29(21.5 \%)$ & $15(51.7 \%)$ & $14(48.3 \%)$ & \multirow[t]{2}{*}{.119} & \multirow[t]{2}{*}{.730} \\
\hline Secondary and above & $106(78.5 \%)$ & $51(48.1 \%)$ & $55(51.9 \%)$ & & \\
\hline \multicolumn{6}{|l|}{ Mothers' education } \\
\hline Up to primary level & $47(34.8 \%)$ & $27(57.4 \%)$ & $20(42.6 \%)$ & \multirow[t]{2}{*}{2.113} & \multirow[t]{2}{*}{.146} \\
\hline Secondary and above & $88(65.2 \%)$ & $39(44.3 \%)$ & $49(55.7 \%)$ & & \\
\hline \multicolumn{6}{|l|}{ Family history of CVD } \\
\hline No & $113(83.7 \%)$ & $60(53.1 \%)$ & $53(46.9 \%)$ & \multirow[t]{2}{*}{4.915} & \multirow[t]{2}{*}{.027} \\
\hline Yes & $22(16.3 \%)$ & $6(27.3 \%)$ & $16(72.7 \%)$ & & \\
\hline
\end{tabular}

\section{DISCUSSION}

In this present study, 17(12.6\%) respondents had inadequate awareness, $52(38.5 \%)$ had moderate awareness and $66(48.9 \%)$ had adequate level of awareness. This finding is consistent with the findings of a study conducted in Kathmandu among 15 to 19 years old students where overall $36.8 \%$ of respondents had good knowledge, $55.6 \%$ had fair knowledge and only $7.6 \%$ had poor knowledge regarding the risk of cardiovascular diseases. ${ }^{11}$ A contradictory finding was found in a study conducted in New Delhi among school children on cardiovascular risk factor and knowledge where $25.4 \%$ respondents had adequate knowledge, while $54.4 \%$ had moderately adequate and $20.21 \%$ had inadequate knowledge. $^{12}$

Regarding the attitude on cardiovascular disease this present study showed that more than half of respondents 
$69(51.1 \%)$ had favorable attitude towards cardiovascular disease. Whereas in a study conducted by Yadav and Wagle showed that majority of the respondents $(47.9 \%)$ had neutral attitude followed by positive (31.9\%) and one fifth possessed negative attitude. $^{11}$

Regarding the risk factors which cause cardiovascular diseases, the findings of this study showed that all of the respondents answered that overweight and harmful use alcohol have higher risk of CVD followed by insufficient physical activity (92.6\%), high bold pressure (97\%), stress, burden and sorrow (89.9\%), use of tobacco (87.4\%) and diabetes (68.9\%). Similar results were found in a study conducted in India by George and Andhuvan on awareness on cardiovascular disease risk factors where all of the respondents considered overweight as a major risk factor $(100 \%)$ for heart disease followed by high cholesterol level (98\%), High blood pressure level (94\%) and Smoking (92\%). ${ }^{13}$ Though heterogeneous population is seen in this study as compared to our study; the findings were still similar on the cardiovascular disease risk factors. It might be due similar educational level of population. A contradictory finding was found in a study conducted in Jhaukhel Duwakot where participants had poor knowledge on the risk factors of heart disease where $29.7 \%$ of the respondents identified hypertension and $11 \%$ identified overweight and physical activity and only $2.2 \%$ identified high blood sugar as causative factors of heart disease. ${ }^{14}$ These contradictory findings might be due to the variations in respondents' age group and due to the variation in education.

Regarding the respondents' awareness on signs of heart disease, this study showed that $89.6 \%$ aware on pain in chest and $81.5 \%$ on difficulty in breathing, $34.1 \%$ on excessive sweating, $25.2 \%$ on dizziness and $28.2 \%$ on swelling of legs as signs of heart disease. Whereas a contradictory finding were found in a study conducted in Jhaukhel where around $60 \%$ of respondents did not know about any signs of the heart attack. Among those who were familiar with those signs, nearly 50\% of respondents knew about only one sign, $37 \%$ knew about any two signs, $11.42 \%$ knew about three signs and $2.53 \%$ knew four signs. ${ }^{14}$ Similarly, a study finding conducted by Juan Quah et al in Singapore among the residents showed that $85.1 \%$ of the respondents agreed that burning pain on the center of chest is the signs of heart attack, followed by $72.9 \%$ shortness of breath, $61.2 \%$ chills and sweating, and $49.8 \%$ as dizziness. ${ }^{15}$

In this study female adolescents scored significantly better knowledge score than male adolescents. Similar findings was observed in a study conducted in India among medical students where female students scored significantly better knowledge score than male students. ${ }^{16}$

This study showed that there was a significant association between gender of respondent and awareness level with Chisquare $\mathrm{p}$ value less than 0.05 (.011). Statistically significant association was not found between type of family and father's education with the level of awareness on CVD ( $p$ value >0.05). Significant association was found on mothers' education and family history of CVD with the level of awareness on CVD ( $p$ value less than 0.05). There were no statistically significant association between gender, type of family, father's education and mother's education with attitude regarding cardiovascular disease at $95 \%$ confidence interval ( $\mathrm{p}$-value >0.05). Significant association was found between family history of CVD and attitude on cardiovascular disease at $95 \%$ confidence interval ( $\mathrm{p}$-value <0.05).

\section{CONCLUSIONS}

Based on the findings of the study it can be concluded that nearly half of respondents had adequate level of awareness regarding cardiovascular diseases whereas more than half of respondents had favorable attitude toward cardiovascular 
disease. Among awareness on cardiovascular disease all of the respondents were aware that overweight and harmful uses of alcohol were the risk factors of cardiovascular diseases.

\section{ACKNOWLEDGEMENT}

The authors are deeply indebted to the adolescents participating in this study and parents and Campus Chief of Makawanpur Multiple Campus for providing permission for the conduction of this study. Special thanks go to Patan Academy of Health Science, School of Nursing \& Midwifery (Lalitpur Nursing Campus) for encouraging me to do this research. Last but not the list my special thanks goes to statistician Nava Raj Poudel, Ph.D Priscilla Samson, Ph. D. Bimala Panthee, Assistant Prof. Vivechana Shakya and Assistant Prof. Roshani Khatri for proving support during the study and Nepal Health Research Council (NHRC) Ethical Review Board for providing the ethical approval.

Funding Source: This research did not receive any specific grant from any funding agencies in the public, commercial or notfor-profit sectors.

Conflict of Interest: The authors have no conflicts of interest to declare

\section{Ethical Approval: Approved}

\section{REFERENCES}

1. World Heart Federation. The state of the heart. Cardiovascular disease report (2017). Retrieved from https://www.world-heartfederation.org/resources/state-heart-cvdreport/

2. Roemmich NJ, LamiaseJM, BalantekinNK, Feda MD, Dom J. Stress, Behavior, and Biology: Risk Factors for Cardiovascular Diseases in Youth. HHS Public Assess Author Manuscripts.2014;42(4):145-152. doi: 10.1249/JES.0000000000000027.

Retrieved from https://www.ncbi.nlm.nih.gov/pmc/articles/ PMC6459183/.
3. Nazar M, Khan AS, Kurmar R, Hafeez A. Effectiveness of health literacy intervention on cardiovascular diseases among university students of Pakistan BMC Health Services Research.2019; 19(504).Retrieved from https://bmchealthservres.biomedcentral.com /articles/10.1186/s12913-019-4348-y

4. Kaur S. A descriptive study to assess the prevalence of cardiovascular risk factors among adolescents in selected schools of Banga, District Shaheed Bhagat Singh Nagar, Punjab. Asian Journal of Nursing Education and Research. 2016;6(3):361370. Doi: 10.5958/2349-2996.2016.00068.9. Retrieved from https://ajner.com/AbstractView.aspx?PID=2 016-6-3-15

5. Ghimire HP, Dhungana A. Cardiovascular Risk Behavior Amongst Adolescents of Lekhnath Muncipality of Kaski district, Nepal. Journal of Gandaki Medical College. 2018;11(1):10-13. Retrieved from file:///C:/Users/Uk/Downloads/20787-

Article\%20Text-65792-1-10-

20180817\%20(1).pdf

6. Shafiq S. Public knowledge of cardiovascular diseases and its risk factors in Srinagar. International Journal of Medical and Health Research. 2017; 3(12): 69-76. Retrieved from file:///C:/Users/Uk/Downloads/3-12-39198.pdf

7. Abdo MN, Mortada ME, Seifi SO. Effect of Knowledge About Cardiovascular Diseases on Healthy Lifestyle Behavior Among Freshmen of Zagazig University: An Intervention Study. The Open Public Health Journal.2019;12:300-308.

Doi:10.2174/1874944501912010300.

Retrieved from https://openpublichealthjournal.com/VOLU ME/12/PAGE/300/FULLTEXT/

8. Arts J, Fernandez LM, Lofgren EI. Coronary Heart Disease Risk Factors in College Students. American Society for Adv Nutrition. 2014;5:177-187. doi:10.3945/an.113.005447.Retrievedfrom file:///C:/Users/Uk/Desktop/Cardiovascular $\% 20$ Study\%20among\%20adolescent/corona ry $\% 20$ disease $\% 20$ risk $\% 20$ factors $\% 20 \mathrm{in} \% 20$ college\% 20students.pdf

9. Pyakurel M, Ghimire A, Pokharel P, Bhatta $\mathrm{R}$ and Parajuli R. Behavioral and Metabolic Risk Factors for Cardiovascular Disease among the School Adolescents of Nepal. 
Juniper online Journal of Public Health. 2017; $\quad 1 \quad$ (3):1-6. 555565. doi:10.19080/JOJPH.2017.01.555565.

Retrieved from https://juniperpublishers.com/jojph/pdf/JOJ PH.MS.ID.555565.pdf.

10. Adhikari N, SapakotaKP, Adhikari S. Cardiovascular Diseases (CVDs) Risk Attitude and Knowledge Level of Major Risk Factors for Cardiovascular Diseases among 15-19 Years Eleventh and TwelfthGrade Students of Lekhnath Municipality. Journal of Community Medicine and Health Education. 2018;8(1):584. doi:10.4172/2161-0711.1000584. Retrieved from https://www.omicsonline.org/openaccess/cardiovascular-diseases-cvds-riskattitude-and-knowledge-level-of-major-riskfactors-for-cardiovascular-diseases-among1519-years-2161-0711-1000584-98361.html

11. YadavKD and Wagle RR. Knowledge and Attitude Regarding Major Risk Factors of Cardiovascular Diseases among 15-19 Year Old Students of Kathmandu District. Health Prospect.2012;11, Retrieved from https://pdfs.semanticscholar.org/27c9/ff35be 60a90454d74cbc3b1a8044902e299d.pdf?_g $\mathrm{a}=2.229696092 .1127403518$.1599494816286066719.1537774490

12. George MG, Sharma KK, Ramakrishnan S, Gupta KS. A study of cardiovascular risk factors and its knowledge among school children of Delhi. Indian Heart Journal. 2014; $66(3)$ : 263-271. doi: 10.1016/j.ihj.2014.03.003. Retrieved from

https://www.ncbi.nlm.nih.gov/pmc/articles/ PMC4121766/.

13. George C and Andhuvan G, 2014. A population - based study on Awareness of Cardiovascular Disease Risk Factors. Indian Journal of Pharmacy Practice. 2014;7(2):
25.doi:10.5530/ijopp.7.2.5Retrievedfrom: http://www.ijopp.org/sites/default/files/IJOP P_7_2_2014_5.pdf, Apr-Jun, 2014

14. Vaidya A, Aryal UR, Krettek A. Cardiovascular health knowledge, attitude and practice/behaviour in an urbanising community of Nepal: a population-based cross-sectional study from JhaukhelDuwakot Health Demographic Surveillance Site. BMJ Open Access. 2013;3:e002976. doi:10.1136/bmjopen-2013-002976.

Retrieved from https://bmjopen.bmj.com/content/bmjopen/3 /10/e002976.full.pdf

15. Juan Quah J L, Yap S, Cheah S O, Ng Y Y, Goh E S, Doctor N, Leong B S, Tiah L, Chong Chia M Y, Hock Ong M E. Knowledge of Signs and Symptoms of Heart Attack and Stroke among Singapore Residents. BioMed Research International. 2014, Article ID 572425, 8 pages http://dx.doi.org/10.1155/2014/572425.

Retrieved from https://downloads.hindawi.com/journals/bm ri/2014/572425.pdf

16. Sadasivam K, NagarajanPK, Ramraj B, Chinnasami B, Nedunchezhian K, Aiyyavoo S. Cardiovascular disease risk factor knowledge assessment among medical students. National Journal of Physiology Pharmacy and Pharmacology. 2016; 6:251257. Retrieved from https://www.njppp.com/fulltext/281457512523.pdf

How to cite this article: Nepal M, Pokharel B, Nepal $\mathrm{P}$ et.al. Awareness and attitude regarding cardiovascular diseases among the adolescents studying in grade 12 in Makawanpur multiple campus in Nepal. Int J Health Sci Res. 2021; 11(5): 261-268. DOI: https://doi.org/10.52403/ ijhsr.20210542 